\title{
Review of Biologic Matrices (Urine, Blood, Hair) as Indicators of Recent or Ongoing Cannabis Use
}

\author{
Frank Musshoff and Burkhard Madea
}

\begin{abstract}
Especially for cannabinoids, analytical procedures for the verification of recent use and generally for the assessment of the extent of drug abuse are of interest in clinical and forensic toxicology. For confirmation of abstinence, urine analysis seems to be a useful tool. Serial monitoring of THC-COOH to creatinine ratios can differentiate between recent drug use and residual THC-COOH excretion ( $\mathrm{THC}-\mathrm{COOH} / \mathrm{creatinine}$ ratio $\geq 0.5$ compared with previous specimen ratio). For an assessment of the extent of cannabis use, the determination of free and bound THC-COOH and especially of THC and 11-OH-THC glucuronides are suggested as useful but need further confirmation. Blood analysis is preferred for the interpretation of acute effects after cannabis abuse. The cannabis influence factor (CIF) was demonstrated as a better tool to interpret the concentrations of THC and its metabolites in blood in forensic cases and therefore it was proposed to assume absolute driving inability because of cannabis intoxication from a CIF $\geq 10$. Additionally, a higher CIF is indicative of a recent cannabis abuse. Also discrimination between occasional use of cannabis and regular drug consumption is possible by analysis of $\mathrm{THC}-\mathrm{COOH}$ in blood samples because of the long plasma half-life of THC$\mathrm{COOH}$ and its accumulation in the blood of frequent cannabis consumers. In routine tests, blood samples have to be taken within a prescribed 8-day-period, and a THC-COOH concentration $>75 \mathrm{ng} / \mathrm{mL}$ is assumed to be associated with regular consumption of cannabis products, whereas plasma THC$\mathrm{COOH}$ concentrations $<5 \mathrm{ng} / \mathrm{mL}$ are associated with occasional consumption. In contrast to other illicit drugs, hair analysis lacks the sensitivity to act as a detector for cannabinoids. THC and especially the main metabolite THC-COOH have a very low incorporation rate into hair and THC is not highly bound to melanin, resulting in much lower concentrations in hair compared with other drugs. Additionally, THC is present in cannabis smoke and also can be incorporated into the hair only by contamination. For the determination of the main metabolite $\mathrm{THC}-\mathrm{COOH}$ in the picogram or femtogram per milligram range, which indicates an active consumption, special
\end{abstract}

Received for publication July 21, 2005; accepted November 4, 2005.

From the Institute of Legal Medicine, University Bonn, Bonn, Germany.

Presented in part at the Congress of the German Society of Traffic Medicine, Bonn, Germany, March 10 to 12, 2005.

Reprints: Frank Musshoff, Institute of Legal Medicine, University Bonn, Stiftsplatz 12, 53111 Bonn, Germany (e-mail: f.musshoff@ uni-bonn.de).

Copyright $(102006$ by Lippincott Williams \& Wilkins analytical procedures, such as $\mathrm{GC} / \mathrm{MS} / \mathrm{MS}$ techniques, are required.

Key Words: cannabinoids, urine analysis, blood analysis, hair analysis, cannabis influence factor, chronic use

(Ther Drug Monit 2006;28:155-163)

C annabis has been self-administrated for its psychoactive effects for many centuries. Currently, cannabis products are the most highly used illicit substances around the world. Government, private industry, and other organizations have implemented rigorous testing programs to discourage use of cannabis and to document abstinence and/or detect recurrent use in previously identified offenders. Other than abstinence control, discrimination between light and heavy users can be necessary for further measures. The implications of positive tests in these settings include loss of employment or driving licence, fines, or imprisonment. Therefore, correction for any factor that might produce a false interpretation of a test result must be performed. Drug detection times depend mainly on the dose and sensitivity of the method used, but also on the preparation and route of administration, duration of use (acute or chronic), matrix that is analyzed, molecule or metabolite sought, $\mathrm{pH}$ and amount of the matrix, and finally the interindividual variation in metabolism. With respect to pharmacokinetic and substance-specific data of cannabinoids, the implications of urine, blood, and hair analysis are discussed.

\section{PHARMACOKINETICS}

Pharmacokinetic data of cannabinoids were extensively reviewed. ${ }^{1-3}$ The major psychoactive constituent of cannabis products is $\Delta^{9}$-tetrahydrocannabinol (THC), which is rapidly assimilated after exposure, and because of its lipophilic nature is distributed to adipose tissue, liver, lung, and spleen. It is then slowly released back into the blood and metabolized, causing a relatively long terminal half-life. Hepatic enzymatic biotransformation yields multiple metabolites with $\mathrm{C}-11$ being the major modification site. Hydroxylation results in the psychoactive compound 11-hydroxy- $\Delta^{9}$-tetrahydrocannabinol (11-OH-THC) and further oxidation in the inactive 11-nor- $\Delta^{9}$-tetrahydrocannabinol-9-carboxylic acid (THC$\mathrm{COOH})$, the most important compound for testing 
purposes, which is excreted into the urine mainly as a glucuronic acid conjugate (Fig. 1).

\section{Absorption}

After inhalation, THC is detectable in plasma only seconds after the first puff of a cigarette with peak plasma concentrations being reached in 3 to 10 minutes after onset of smoking. ${ }^{4-8}$ Bioavailability varies according to depth of inhalation, puff duration, and breathhold. Approximately $30 \%$ of $\mathrm{THC}$ is assumed to be destroyed by pyrolysis. A systemic bioavailability of $23 \pm 16 \%{ }^{6}$ and $27 \pm 10 \%{ }^{9}$ for heavy users versus $10 \pm 7 \%$ and $14 \pm 1 \%$ for occasional users of the drug was reported.

After oral use, absorption is slow resulting in maximal THC plasma concentrations usually after 1 to 2 hours ${ }^{7,10}$; in some cases maximal plasma concentrations were observed as late as 4 to 6 hours, 7,11 and several subjects showed more than one plasma peak. An extensive first-pass liver metabolism reduces the oral bioavailability of THC to $6 \% \pm 3 \%$ (range, $4-12 \%$ ). ${ }^{7}$

\section{Distribution}

Approximately $90 \%$ of $\mathrm{THC}$ in the blood is distributed in the plasma and another $10 \%$ in red blood cells. ${ }^{12,13}$ For interpretation of blood analysis results, it has to be taken into account that plasma cannabinoid concentrations are approximately twice those found in whole blood samples because of the low partition coefficient of the drug into erythrocytes. ${ }^{14-17}$ Of plasma THC $95 \%$ to $99 \%$ is bound to plasma proteins, mainly to lipoproteins and less to albumin. Because of the high protein-binding complicating initial disposition, the initial volume of distribution of THC is small for a lipophilic drug. It was reported to be $2.55 \pm 1.93 \mathrm{~L}$ in drug-free users and $6.38 \pm 4.1 \mathrm{~L}$ in regular users. ${ }^{18}$ The steady-state volume of distribution has been estimated to be approximately $10 \mathrm{~L} / \mathrm{kg} .{ }^{10,18,19}$ THC rapidly penetrates highly vascularized tissues resulting in a rapid decrease in plasma concentration. ${ }^{20}$ However, intensive accumulation occurs in less vascularized tissues and finally in body fat, ${ }^{21-23}$ which represents the major long-term storage site, resulting in concentration ratios between fat and plasma of up to $10^{4}: 1 .^{24}$ The exact composition of the material accumulated in fat is still unknown; a substantial proportion seems to consist of fatty acid conjugates of 11-OH-THC. ${ }^{25,26}$

\section{Metabolism}

THC is mainly metabolized in the liver by microsomal hydroxylation and oxidation catalyzed by enzymes of the cytochrome P450 (CYP) complex. Average plasma clearance rates have been reported to be $11.8 \pm 3 \mathrm{~L}$ per hour for women and $14.9 \pm 3.7 \mathrm{~L}$ per hour for men. ${ }^{10}$ Others have determined mean clearance rates of approximately $36 \mathrm{~L}$ per hour for naive cannabis users and approximately $60 \mathrm{~L}$ per hour for regular users.

\section{Time Course of Plasma Concentrations}

The course of plasma THC concentrations after inhalation resembles that after intravenous administration. Smoking a single cigarette containing approximately 16 or $34 \mathrm{mg}$ of THC caused average peak concentrations of 84.3 (range, 50-129) ng/mL for the lower dose and 162.2 (range, 76-267) ng/mL for the higher dose, respectively. ${ }^{4}$ The THC concentrations rapidly decreased to 1 to $4 \mathrm{ng} / \mathrm{mL}$ within 3 to 4 hours. After inhalation, the maximal THC plasma concentration was reported to exceed the maximal THC-COOH concentration by 3 -fold and the maximal 11-OH-THC concentration by 20 -fold. However, THC/11-OH-THC ratios declined and reached a ratio approximately $2: 1$ after 2 to 3 hours. Peak concentrations for THC were observed approximately 8 (range, 6-10) minutes after onset of smoking, whereas 11-OH-THC peaked at 15 (range, 9-23) minutes and THC-COOH at 81 (range, 32-133) minutes. After oral administration, maximal $\mathrm{THC}$ plasma concentrations were 4.4 to $11 \mathrm{ng} / \mathrm{mL}$ for THC $20 \mathrm{mg}^{7}$ and 2.7 to $6.3 \mathrm{ng} / \mathrm{mL}$ for THC $15 \mathrm{mg} .{ }^{11}$ Much higher amounts of $11-\mathrm{OH}-\mathrm{THC}$ are formed than with inhalational use, and the ratio of THC and 11-OH-THC plasma concentrations was approximately $2: 1$ to $1: 1 .^{10}$

The mean window of detection for $\mathrm{THC}-\mathrm{COOH}$ in plasma samples was 3.5 (range, 2-7) days after smoking a cigarette containing $16 \mathrm{mg}$ of $\mathrm{THC}$ and 6.3 (range, 2-7) days after a $34-\mathrm{mg}$ dose. ${ }^{4}$ In 52 volunteers admitted to a detoxification, THC-COOH could be detected in serum from 3.5 to 74.3 hours with initial concentrations between 14 and $49 \mathrm{ng} / \mathrm{mL}^{27}$ This was considerably less than the THC-COOH detection time of 25 days in a single chronic user with an initial concentration of $350 \mathrm{ng} / \mathrm{mL}{ }^{28}$

\section{Elimination}

Approximately 6 hours after intravenous administration of THC, a pseudoequilibrium is reached between

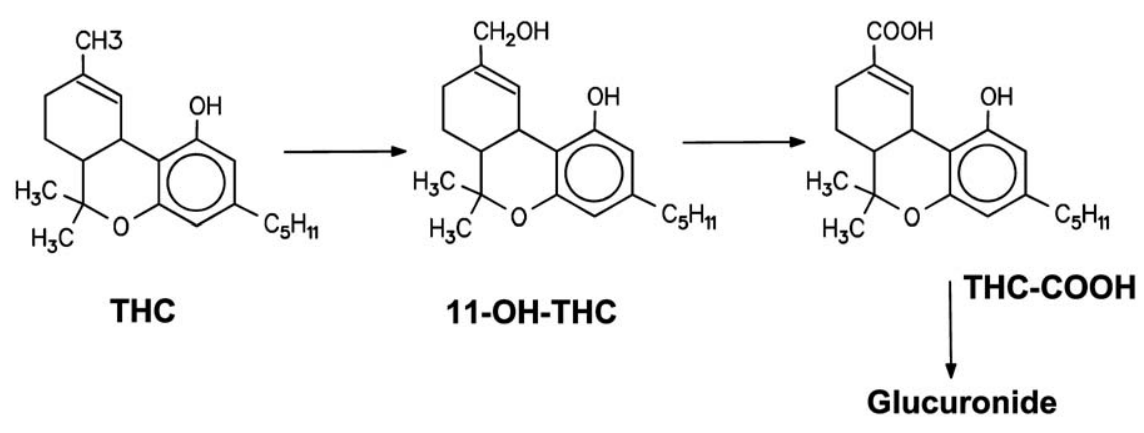

FIGURE 1. Main metabolic route for $\Delta^{9}$-tetrahydrocannabinol (THC). 
plasma and tissues, ${ }^{29}$ and usually the THC concentration in plasma is $<2 \mathrm{ng} / \mathrm{mL}$ at this time and then decreases more slowly with increasing time from use. The slow elimination is based on the slow rediffusion of THC from body fat and other tissues into the blood. After smoking a low-dose THC cigarette $(16 \mathrm{mg})$, the limit of detection of $0.5 \mathrm{ng} / \mathrm{mL}$ of THC in plasma was reached after 7.2 (range, 3-12) hours, and after a high-dose cigarette $(35 \mathrm{mg})$, the limit of detection was reached after 12.5 (range, 6-27) hours. ${ }^{4}$ THC-COOH was detectable for a considerably longer time of 3.5 (range, 2-7) days after the low dose and 6.3 (range, 3-7) days after smoking the high dose. The half-life of the terminal phase $\left(t_{1 / 2 \beta}\right)$ ranged from 25 to 36 hours for THC, from 12 to 36 hours for $11-\mathrm{OH}-\mathrm{THC}$, and from 25 to 55 hours for THC-COOH after oral or intravenous administration. ${ }^{10}$ However, as in similar reports the plasma concentrations were not measured long enough to determine the half-life accurately. The elimination half-life for THC metabolites from plasma is longer than that for THC itself. In a further study, the mean $t_{1 / 2 \beta}$ of THC for frequent users was approximately 19 hours and that of the overall metabolites 53 hours. ${ }^{18}$ In a further study, the mean $t_{1 / 2 \beta}$ for THC-COOH and conjugated THC-COOH was 5.2 days and 6.8 days, respectively, for the frequent users and 6.2 days and 3.7 days, respectively, for the infrequent cannabis users based on data collected for 12 days. ${ }^{30}$ The differences were not statistically significant.

The high lipophilicity of $\mathrm{THC}$, resulting in high tubular reabsorption, explains the low renal excretion of the unchanged drug. Furthermore, excretion is delayed by an extensive enterohepatic recirculation of metabolites and the high protein binding of cannabinoids, resulting in a predominant excretion with the feces. A urinary excretion half-life of THC-COOH of approximately 30 hours was observed with a 7-day monitoring period and of 44 to 60 hours with a 14-day period. ${ }^{31}$ Others calculated similar average urinary excretion half-lives of approximately 2 days with a 12 -day monitoring period ${ }^{30}$ and approximately 3 (range, 0.9-9.8) days when THC$\mathrm{COOH}$ was measured for 25 days. $^{32}$ Free THC-COOH is not excreted in significant concentrations; the main compound is the glucuronide of THC-COOH. In a recent study, significant concentrations of neutral cannabinoids were found by using an enzymatic hydrolysis step in the extraction procedure, with THC concentrations peaking at 21.5 (range, 3.2-53.3) ng/mL 2 hours after smoking $27 \mathrm{mg}$ of THC in a cigarette, 11-OH-THC peaking at $77.3 \pm 29.7 \mathrm{ng} / \mathrm{mL}$ after 3 hours and THC-COOH peaking at $179.4 \mathrm{ng} / \mathrm{mL} \pm 146.9 \mathrm{ng} / \mathrm{mL}$ after 4 hours. $^{33}$

\section{Stability of Cannabinoids}

A general problem for interpretation of analytical results is the phenomenon that cannabinoid compounds in urine are relatively unstable. Decrease in the urine concentrations of cannabinoids is generally produced as a consequence of degradation processes of oxidation. ${ }^{34}$ Storage of urine samples under basic conditions can cause oxidation of phenol to quinone. Others have indicated that the storage temperature is the main factor related to the degradation. Appreciable losses of approximately $22.4 \%$ were observed in some urine samples after being stored at room temperature for 10 days. ${ }^{35}$ Lower losses were observed when samples were refrigerated for 4 weeks $(8.1 \%)$. Important mean losses of $8 \%, 15.8 \%$, and $19.6 \%$ were found when urine samples were frozen for 40 days, 1 year, and 3 years, respectively. However, average losses $(>5 \%)$ could be observed after 1 day, which could be mainly the result of the decrease of solubility of THC$\mathrm{COOH}$ or absorption processes.

Recently it was demonstrated that during storage THC-COOH is liberated from its glucuronide in a timeand temperature-dependent manner with wide interindividual differences. ${ }^{36,37}$ At $20^{\circ} \mathrm{C}$, a marked change in concentration could be observed within 2 days of storage. A loss in total THC-COOH concentration could be observed and was attributed to decarboxylation of THC$\mathrm{COOH}$ or partially to fungal or bacterial conversion. According to the authors, acidification to $\mathrm{pH} 5$ can help to enhance the stability of analytes; however, liberation of THC-COOH from its glucuronide could not be completely prevented. In general, deep, frozen storage was demanded.

\section{INTERPRETATION OF CANNABINOID CONCENTRATIONS IN URINE, BLOOD, AND HAIR SAMPLES}

\section{Time Course and Interpretation of Cannabinoid Urine Concentration}

Individuals with a history of cannabis abuse are required to submit to random urine drug testing for several reasons (eg, driving ability, family court, workplace drug testing). Several factors can influence the concentrations and the duration of detectability of the urinary THC metabolites. These factors include frequency of cannabinoid usage, timing of specimen collection, body fat content, and degree of urine dilution with positive test results persisting as long as 4 to 5 weeks in some individuals. Furthermore, assay cutoff concentrations and sensitivity and specificity of the immunoassay or chromatographic procedure do affect drug detection times.

In general, immunoassays (IA) are adopted as a preliminary test method in drug testing programs. However, false-positive (or false-negative) results occur from structurally related drugs that are recognized by the antibodies or occasionally by artefacts, such as adulterants affecting $\mathrm{pH}$, detergents, and other surfactants. For this reason, any positive result must be confirmed by a chromatographic technique, preferably with mass spectral identification. Gas chromatography and liquid chromatography coupled with mass spectrometry (GC/MS or $\mathrm{LC} / \mathrm{MS}$ ) are the "gold standard" procedures. In some previous studies, the window of detection for THC$\mathrm{COOH}$ or cannabinoids in urine samples was demonstrated with ranges from several days in infrequent 


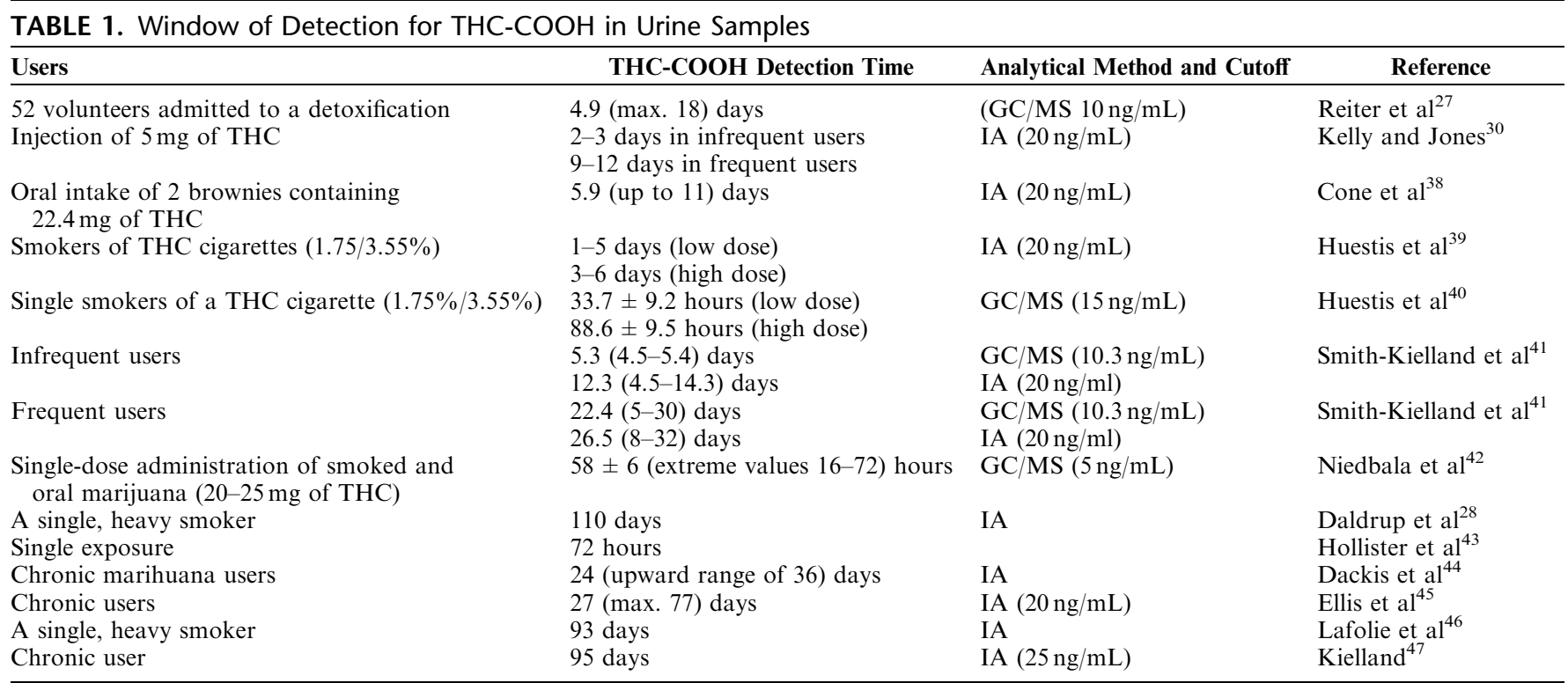

users $^{27,30,38-42}$ to weeks or months ${ }^{28,43-47}$ in frequent users (Table 1). In Figure 2, the cannabinoid elimination in plasma and urine of a heavy cannabis user is demonstrated. The intermittent urinary elimination with urine is a great problem for verification of abstinence or recent abuse in drug testing programs. Peaks in urine cannabinoid elimination patterns are not necessarily based on a recent abuse of cannabis, as demonstrated by negative results in a simultaneous blood analysis.

Therefore, in some clinical trials verification of abstinence from cannabinoid use after initial identification requires documentation of declining $\mathrm{THC}-\mathrm{COOH}$ levels during an extended time period. Ellis et $\mathrm{al}^{45}$ studied the excretion patterns of cannabinoid metabolites after last use. Urine samples were tested daily by the EMIT (Syva Company) cannabinoid assay (cutoff $20 \mathrm{ng} / \mathrm{mL}$ ) until subjects had 10 consecutive cannabinoid-negative tests. Urine samples from 86 (chronic) users were still cannabinoid-positive for up to 46 (mean, 16) days before the first negative result, and it took up to 77 (mean, 27) days to decrease to less than the $20 \mathrm{ng} / \mathrm{mL}$ cutoff for 10 consecutive days. In 52 volunteers admitted to a detoxification program, THC-COOH was detected in urine samples for up to 18 days, when the initial levels in urine were approximately 10 times higher than those reported by Huestis et al. ${ }^{40}$ However, such long elimination times were observed only in a few cases, otherwise such extremely long windows of detection also were described in other (single) cases. ${ }^{28,44}$

As explained by Fraser et $\mathrm{al}^{48}$ the antibodies used in diagnostic kits 15 to 20 years ago cross-reacted with many cannabinoid metabolites excreted in the urine. Furthermore, in several of the earlier studies, the individuals considered to be excreting cannabinoid-positive urine specimens for several weeks or months were not maintained in a secure facility to exclude further drug use. Current studies on cannabinoid metabolite excretion times indicated much shorter metabolite excretion times than earlier publications. ${ }^{39,40}$ Urine samples were screened by a commercially available immunoassay (cutoff $50 \mathrm{ng} / \mathrm{mL}$ ) followed by confirmation by GC/MS for the major metabolite THC-COOH (cutoff $15 \mathrm{ng} / \mathrm{mL}$ ). Occasional users of marijuana had positive urine specimens for 72 to 96 hours after receiving the test dose of marijuana. In heavy users, persons remained positive for cannabinoids for 7 to 10 days after the last drug use in the study.

Creatinine corrected THC-COOH levels have been described in a hypothetical example to verify resumption of cannabis abuse. ${ }^{46,49}$ Urine specimens are analyzed for creatinine as an index of urine dilution or potential adulteration by dilution. There are a lot of studies in which examination of a series of absolute values

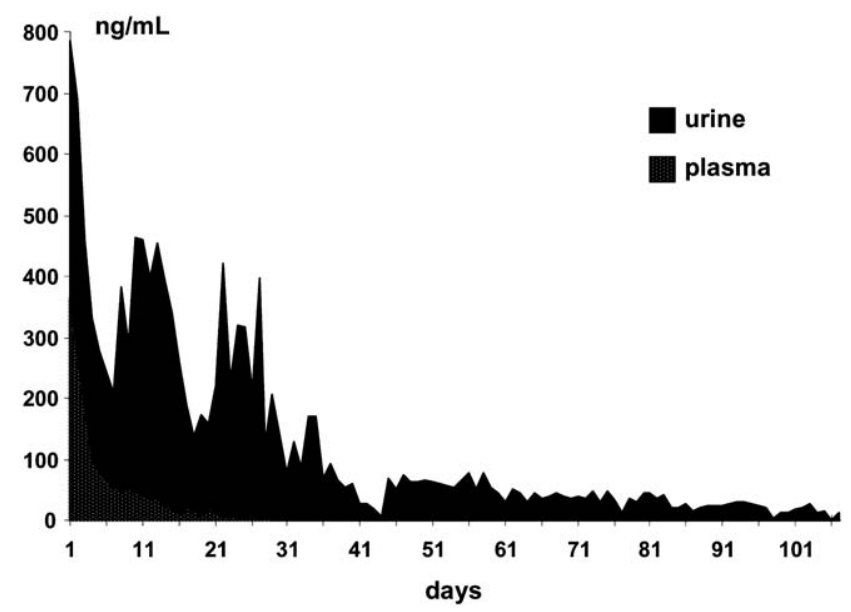

FIGURE 2. Elimination of cannabinoids from serum and urine of a formerly heavy smoker of cannabis (modified according $\left.\mathrm{to}^{28}\right)$. 
suggested resumption of cannabis use, whereas values normalized to urinary creatinine showed a linear decline with terminal half-lives from 10.8 to 32 days, confirming abstinence from cannabis abuse. However, also in these studies some peaks were observed in urine cannabinoid elimination patterns, and because these were not based on a recent abuse of cannabis, serial monitoring seemed to be necessary.

Huestis and $\mathrm{Cone}^{50}$ reported serial monitoring of THC-COOH to creatinine ratios in $>1800$, paired, urine specimens. They studied 6 male subjects who had smoked marijuana cigarettes of known strength in a controlled, clinical setting. In urine samples collected at least 24 hours apart, different $\mathrm{THC}-\mathrm{COOH}$ to creatinine ratios were assessed to determine optimal criteria for differentiating between recent marijuana use and residual metabolites excreted after previous cannabis abuse. The overall prediction accuracy was $85.4 \%$ with a $5.6 \%$ falsepositive rate and $7.4 \%$ false-negative rate when using a normalized $\mathrm{THC}-\mathrm{COOH}$ to creatinine ratio $\geq 0.5$ : for testing to be consistent with new cannabis abuse, the second $\mathrm{THC}-\mathrm{COOH}$ to creatinine ratio must be $>50 \%$ of the first ratio. In an earlier study, Manno et $\mathrm{al}^{51}$ recommended a ratio of $\geq 1.5$ or $150 \%$ of the second versus the first total cannabinoid (EMIT dau) to creatinine ratio. According to an evaluation of this $150 \%$ ratio by Huestis and Cone, ${ }^{50}$ this ratio was only $74.2 \%$ accurate with a $24 \%$ false-negative rate and a $0.1 \%$ false-positive rate. Fraser and Worth ${ }^{52}$ applied both formulas to predict recent use of marijuana and recommended that the Huestis ratio is best for clinical settings because of the lower false-negative rate. The Manno formula was recommended for forensic purposes because it has a lower false-positive rate. However, the Manno formula was based solely on immunoassay rates only and did not include a quantitative (GC/MS) analysis of $\mathrm{THC}-\mathrm{COOH}$, which is recommended in forensic cases. In recent studies, the Huestis criteria were successfully applied when monitoring subjects in an uncontrolled setting, with the minimum time period between urine specimens being at least 48 or 96 hours. ${ }^{53,54}$

Smith-Kielland et $\mathrm{al}^{41}$ studied the urinary excretion of THC-COOH in infrequent and frequent drug users and measured mean excretion half-lives of 1.3 and 1.4 days, respectively. In the latter group, apparent terminal urinary excretion half-lives up to 10.3 days were observed. The last positive specimens were found after 5 days $(\mathrm{GC} /$ MS cutoff, $10.3 \mathrm{ng} / \mathrm{mL}$ ) and 12 days (EMIT cutoff, $20 \mathrm{ng} /$ $\mathrm{mL}$ ) in infrequent users and after 22 and 27 days, respectively, in frequent users. Increases in the immunologic results were sometimes found without concomitant increase in $\mathrm{THC}-\mathrm{COOH}$ or normalized $\mathrm{THC}-\mathrm{COOH}$. However, considerable variations were observed in THC$\mathrm{COOH}$ concentration and normalized THC-COOH without suspicion of a new intake.

There exist some approaches to assess the extent of cannabis use by means of urine analyses. A difference was observed in the excretion of unconjugated $\mathrm{THC}-\mathrm{COOH}$ between frequent and infrequent users. In infrequent users, no unconjugated THC-COOH was detected in urine samples for the first 8 hours after smoking, whereas this metabolite was detected in the urine from frequent users. $^{55}$

In a further procedure for assessing the extent of cannabis use, free and bound $\mathrm{THC}-\mathrm{COOH}$ as well as free THC and 11-OH-THC and the glucuronides of both compounds were measured in urine samples. ${ }^{56}$ Within 4 to 6 days, the concentrations of free and glucuronidated THC-COOH in samples of heavy cannabis users decreased to those ranges present in urine samples of moderate or light users. Free THC or free 11-OH-THC was never found in any sample. In light users, neither THC glucuronide nor 11-OH-THC glucuronide was detectable. The determination of conjugated THC and 11-OH-THC in addition to free and glucuronidated THC-COOH was suggested as an aid in assessing the frequency of cannabis use. However, this procedure is limited to samples obtained within a few days after the last consumption.

Recently, Manno et $\mathrm{al}^{33}$ measured THC and several metabolites, such as 11-OH-THC and THC-COOH, in hydrolyzed plasma and urine samples of human volunteers in an attempt to determine a time of last drug abuse based on absolute or relative amounts of these analytes. They concluded that urinary concentrations of THC $>1.5 \mathrm{ng} / \mathrm{mL}$ suggested cannabis use within an 8 hours time frame and indicated that 11-OH-THC declined more gradually than THC. Furthermore they concluded that quantitation of THC-COOH can neither accurately predict the time of the last cannabis use nor suggest any relationship between urine drug concentrations and psychomotor performance.

\section{Time Course and Interpretation of Cannabinoid Plasma Concentration}

Individual drug concentrations and ratios of metabolites to THC have been suggested to be potentially useful indicators of recent cannabis use. ${ }^{11,57,58}$ Generally these attempts have not been successful in predicting the time of exposure with reasonable accuracy. Huestis et al ${ }^{59}$ reported on 2 mathematical models that are useful to predict the time of cannabis use. The models are based on THC plasma concentrations (Model I) and THC-COOH/ THC ratios (Model II). Model I was derived from linear regression analysis of plasma THC concentration and elapsed time after marijuana smoking: $\log \mathrm{h}=-0.698$ $\log \mathrm{THC}+0.687(r=0.949)$. Model II was derived from linear regression analysis of plasma THC-COOH/THC ratios versus elapsed time after marijuana smoking: log $\mathrm{h}=0.576 \log$ THC-COOH/THC $-0.176(r=0.919)$. Both models were validated with data from 9 clinical studies involving marijuana administration and GC/MS determination of cannabinoids in plasma samples $(n=168)$, for which dose and time of drug use were known. Model I accurately predicted the elapsed time after marijuana use for infrequent and frequent smokers but was less accurate after oral administration. Model II accurately predicted the time of marihuana use for 
samples from infrequent smokers and after marijuana ingestion but was somewhat less accurate than Model I for samples from frequent smokers. However, Model II tended to overestimate the postconsumption interval for samples from frequent smokers. Recently, based on data from controlled oral THC administration trials, further evidence for the usefulness of the predictive models for estimating the time elapsed since drug use was provided, even after multiple oral use (hemp oil and dronabinol). ${ }^{60}$

In Germany, the so-called cannabis influence factor (CIF) is recommended as a useful tool to interpret acute effects in cases of driving under influence and to indicate a recent cannabis use. The CIF is calculated:

$$
\mathrm{CIF}=\frac{\frac{\mathrm{THC}[\mathrm{ng} / \mathrm{mL}]}{314.5}+\frac{11-\mathrm{OH}-\mathrm{THC}[\mathrm{ng} / \mathrm{mL}]}{330.5}}{\frac{\text { THC-COOH }[\mathrm{ng} / \mathrm{mL}] \times 0.01}{344.5}}
$$

THC concentrations and the CIFs were compared with the frequency of deficiency symptoms or driving errors in some hundred cases. ${ }^{61,62}$ There were a lot of cases with a relatively low THC concentration (and a high CIF) in which strong cannabis effects have been documented, and other cases with a relatively high THC concentration (and a low CIF) in which no effects have been observed. The CIF was demonstrated to be an additional tool to interpret the concentrations of $\mathrm{THC}$ and its metabolites in plasma/blood in forensic cases, and therefore it was proposed to assume absolute driving inability as a result of cannabis intoxication from a CIF $\geq 10{ }^{63}$ Additionally, a higher CIF is indicative for a recent cannabis abuse. In Figure 3 an example for the better correlation between conspicuous driving symptoms and the CIF compared with the THC concentration is demonstrated. However, according to new results traffic accidents occur more often in the subacute phase of intoxication, ie, 2 to 6 hours after consumption of cannabis products characterized by a moderate CIF, whereas in the acute intoxication phase defined by a high CIF (during the first 2 hours) an extremely reserved way of driving was observed together with symptoms of a central attenuation and conspicuous driving behavior. ${ }^{64}$

In parts of Germany, another procedure is used for a discrimination between a one-off/occasional use of cannabis and regular drug consumption. ${ }^{65}$ Because of the long plasma half-life of THC-COOH of approximately 6 days, ${ }^{30}$ its accumulation in the blood of regular cannabis consumers can be observed. In routine tests, blood samples have to be taken within a prescribed 8-day period. Considering the empirical finding that a THC$\mathrm{COOH}$ plasma concentration $>150 \mathrm{ng} / \mathrm{mL}$ was found only in regular cannabis users some hours after the last consumption $^{61}$ and that the $t_{1 / 2 \beta}$ for THC-COOH is approximately 6 days, a THC-COOH concentration $>75 \mathrm{ng} /$ $\mathrm{mL}$ within the 8-day period was assumed to be associated with regular consumption of cannabis products. Plasma THC-COOH concentrations below $5 \mathrm{ng} / \mathrm{mL}$ were associated with occasional consumption, based on results from studies on marihuana smoking, when THC-COOH
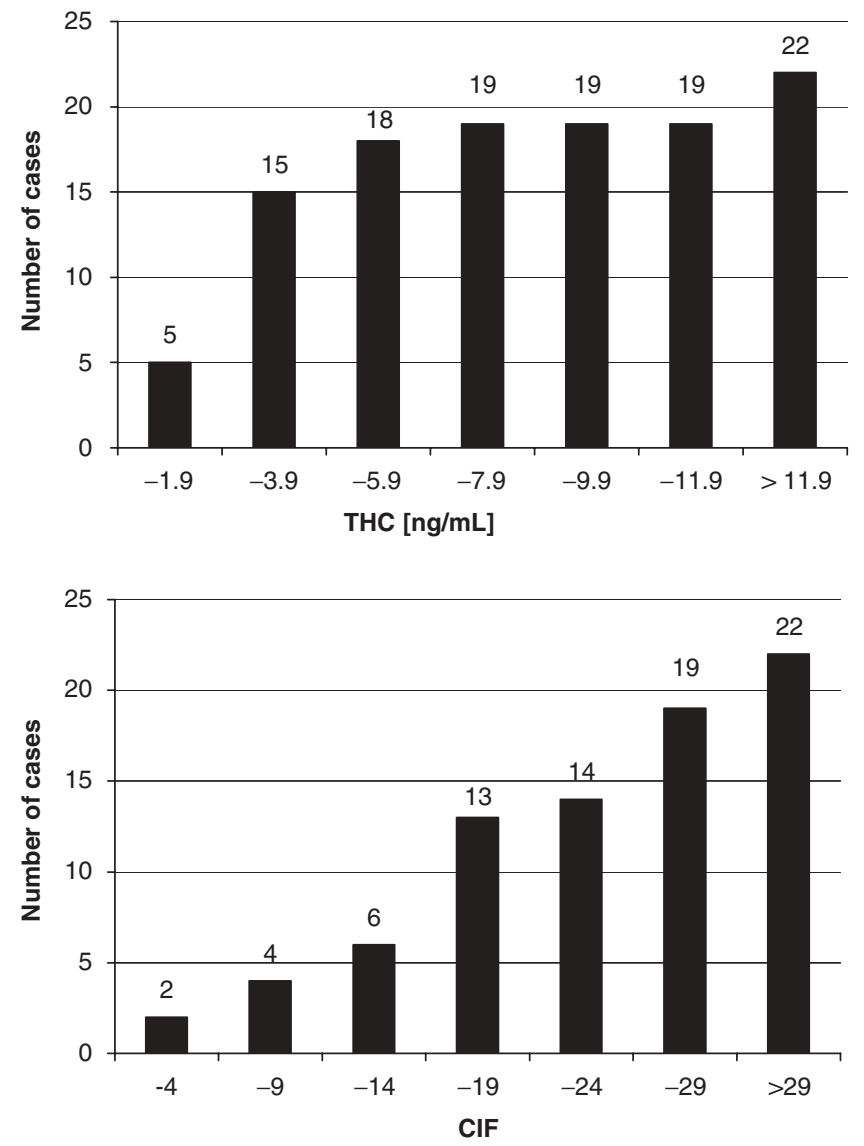

FIGURE 3. Incidence of weaving correlated with the THC concentration in plasma and the CIF $(n=22)$. The CIF correlates slightly better with the conspicuous driving performance compared with the THC concentration itself (data modified according to ${ }^{63}$ ).

levels $<5 \mathrm{ng} / \mathrm{mL}$ were reached after 2 to 3 days. ${ }^{4}$ In Table 2 the interpretation of THC-COOH plasma concentrations with following measures concerning the driving ability together with own data are demonstrated.

For all models described above, the stability of analytes, especially of the THC-COOH glucuronide has to be taken into account. It was demonstrated that for a given storage time and temperature the decrease in plasma was higher than that in urine. ${ }^{36}$

\section{Hair Analysis}

Hair analysis complements blood and urine analyses and is routinely applied in clinical and forensic toxicology. ${ }^{66,67}$ Hair tests offer some advantages over other assays; the collection of hair specimens is less embarrassing and intrusive for study subjects. Hair analysis allows a cumulative reflection of long-term abuse. Another advantage of hair samples is that they can be stored at room temperature and do not need to be directly analyzed after collection. Furthermore, the window of detection of drug abuse in hair tests is considerably wider than that of blood or urine assays 
TABLE 2. Interpretation of THC-COOH Plasma Concentrations With Following Measures Concerning the Driving Ability Together With Own Data

\begin{tabular}{|c|c|c|c|c|}
\hline Results & Interpretation & Measures & 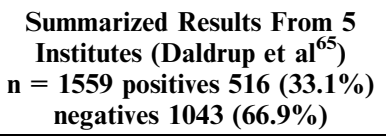 & $\begin{array}{c}\text { Bonn 2000-2004 n = 1.003 } \\
\text { positives } 84(8.4 \%) \\
\text { negatives } 919(91.6 \%) \\
\end{array}$ \\
\hline $\begin{array}{l}\mathrm{THC}-\mathrm{COOH}<5 \mathrm{ng} / \mathrm{mL} \\
\mathrm{THC}=0\end{array}$ & On-off/occasional use & None & $212(41.1 \%)$ & $10(11.9 \%)$ \\
\hline $\begin{array}{l}\text { THC-COOH }<5 \mathrm{ng} / \mathrm{mL} \\
\mathrm{THC}>0\end{array}$ & At least occasional use & $\begin{array}{l}\text { Medical-psychologic } \\
\text { examination because } \\
\text { loss of control }\end{array}$ & $21(4.1 \%)$ & - \\
\hline $\begin{array}{l}\text { THC-COOH 5-74.9 ng/ } \\
\text { mL THC }=0\end{array}$ & $\begin{array}{l}\text { Occasional use with } \\
\text { suspicion of regular } \\
\text { consumption }\end{array}$ & $\begin{array}{l}\text { Personal talk with further } \\
\text { check-up }\end{array}$ & $99(19.2 \%)$ & $69(82.1 \%)$ \\
\hline $\begin{array}{l}\text { THC-COOH 5-74.9 ng/ } \\
\text { mL THC }>0\end{array}$ & $\begin{array}{l}\text { Occasional use with } \\
\text { suspicion of regular } \\
\text { consumption }\end{array}$ & $\begin{array}{l}\text { Medical-psychologic } \\
\text { examination because } \\
\text { loss of control }\end{array}$ & $149(28.9 \%)$ & $1(1.2 \%)$ \\
\hline THC-COOH $\geq 75 \mathrm{ng} / \mathrm{mL}$ & Regular consumption & $\begin{array}{l}\text { Disqualification from } \\
\text { driving }\end{array}$ & $35(6.8 \%)$ & $4(4.8 \%)$ \\
\hline
\end{tabular}

and is only limited by the length of the hair; it typically ranges from a week to several months (hair growth approximately $1 \mathrm{~cm}$ per month). There are multiple mechanisms for the incorporation of cannabinoids in hair. Besides incorporation from blood capillaries into the hair bulb, substances also may diffuse into hair from sebum or sweat secreted onto the hair shaft or onto the skin surface. Because cannabis is primarily smoked, there also is a probability for environmental contamination of hair with cannabinoids in cannabis smoke. THC, and especially the main metabolite $\mathrm{THC}-\mathrm{COOH}$, have a very low incorporation rate (ICR) into hair, with a 3600-fold difference between the ICR of cocaine and that of THC$\mathrm{COOH}$, the latter being the drug with the lowest ICR investigated so far. ${ }^{68}$ Additionally, the comparatively neutral and lipophilic THC is not highly bound to melanin, resulting in much lower concentrations of THC in hair compared with other drugs. Most analytical procedures for the analysis of cannabinoids in hair samples involve only THC, sometimes together with cannabinol and cannabidiol.

In comparative studies, a relatively high number of cases was described in which hair tested "negative" but urine was "positive" for cannabinoids in drug users. ${ }^{69-71}$ This phenomenon is indicative of the assays' failure or the assays' limited sensitivity to detect THC in the hair. Additionally, all these substances are present in cannabis smoke and also can be incorporated into the hair only by contamination. Generally, washing procedures should prevent false-positive results, but finally it cannot be excluded that traces of THC may be found in hair after mere passive cannabis smoke exposure. THC-COOH is not present in cannabis smoke, thus eliminating the possibility of passive exposure from the environment. However, in hair samples THC-COOH is present in the fg- to $\mathrm{pg} / \mathrm{mg}$ range, which requires special analytical procedures, such as GC/MS/MS techniques ${ }^{72,73}$ or $\mathrm{GC} /$ MS in negative ion chemical ionization mode (GC/MSNCI). ${ }^{74-76}$ Unlike for other illicit drugs, hair lacks the sensitivity to act as a detector for cannabinoids. The most appropriate strategy to prove cannabis consumption is an immunochemical initial test followed by a GC/MS/MS confirmation of THC-COOH. ${ }^{77}$

\section{CONCLUSIONS}

Biologic specimens, such as urine, blood, and hair, are useful as objective indicators of substance abuse. However, because all have different inherent limitations in measuring the timing, duration, frequency, and intensity of drug use, the material of choice depends on the circumstances and special analytical problems. For confirmation of abstinence from cannabis abuse, urine analysis seems to be a useful tool. Serial monitoring of THC-COOH to creatinine ratios can differentiate between recent drug use and residual THC-COOH excretion. For an assessment of the extent of cannabis use, the determination of free and bound THC-COOH as well as THC and 11-OH-THC glucuronides in urine samples are suggested as an useful aid. This procedure is limited to samples obtained within a few days after the last consumption and further studies are necessary for a validation of the procedure. Blood analysis is preferred for the interpretation of acute effects after cannabis abuse. The cannabis influence factor was demonstrated to be an additional tool to interpret the concentrations of THC and its metabolites in blood in forensic cases. Additionally, discrimination between one-off/occasional use of cannabis and regular drug consumption is possible by analysis of THC-COOH in blood samples because of the long plasma half-life of THC-COOH and its accumulation in the blood of frequent cannabis consumers. Unlike for other illicit drugs, hair analysis lacks the sensitivity to act as a detector for cannabinoids. THC and especially the main metabolite, THC-COOH, have a very low incorporation rate into hair and the comparatively neutral and lipophilic THC is not highly bound to melanin, resulting in much lower concentrations of THC 
in hair as opposed to other drugs. Additionally, THC is present in cannabis smoke and also can be incorporated into the hair only by contamination. For the determination of the main metabolite, THC-COOH, which indicates active consumption, special analytical procedures like GC/MS/MS techniques are required.

\section{REFERENCES}

1. Grotenhermen F. Pharmacokinetics and pharmacodynamics of cannabinoids. Clin Pharmacokinet. 2003:42:327-360.

2. Iten PX. Fahren unter Drogen- oder Medikamenteneinfluss-Forensische Interpretation und Begutachtung. Institut für Rechtsmedizin der Universität Zürich; 1994.

3. Huestis MA. Pharmacokinetics and metabolism of the plant cannabinoids Delta-9-tetrahydrocannabinol, cannabidiol and cannabinol. In: Pertwee R, ed. Cannabinoids. New York: SpringerVerlag; 2005:657-690.

4. Huestis MA, Henningfield JE, Cone EJ. Blood cannabinoids. I. Absorption of THC and formation of 11-OH-THC and THCCOOH during and after smoking marijuana. J Anal Toxicol. 1992;16: 276-282.

5. Hollister LE, Gillespie HK, Ohlsson A, et al. Do plasma concentrations of delta 9-tetrahydrocannabinol reflect the degree of intoxication? J Clin Pharmacol. 1981;21:171S-177S.

6. Lindgren JE, Ohlsson A, Agurell S, et al. Clinical effects and plasma levels of delta 9-tetrahydrocannabinol (delta 9-THC) in heavy and light users of cannabis. Psychopharmacology (Berl). 1981;74: 208-212.

7. Ohlsson A, Lindgren JE, Wahlen A, et al. Plasma delta-9 tetrahydrocannabinol concentrations and clinical effects after oral and intravenous administration and smoking. Clin Pharmacol Ther. 1980;28:409-416.

8. Perez-Reyes M, Di GS, Davis KH, et al. Comparison of effects of marihuana cigarettes to three different potencies. Clin Pharmacol Ther. 1982;31:617-624.

9. Ohlsson A, Lindgren JE, Wahlen A, et al. Single dose kinetics of deuterium labeled delta 1-tetrahydrocannabinol in heavy and light cannabis users. Biomed Mass Spectrom. 1982;9:6-10.

10. Wall ME, Sadler BM, Brine D, et al. Metabolism, disposition, and kinetics of delta-9-tetrahydrocannabinol in men and women. Clin Pharmacol Ther. 1983;34:352-363.

11. Law B, Mason PA, Moffat AC, et al. Forensic aspects of the metabolism and excretion of cannabinoids following oral ingestion of cannabis resin. J Pharm Pharmacol. 1984;36:289-294.

12. Widman M, Agurell S, Ehrnebo M, et al. Binding of (+)- and (-)delta-1-tetrahydrocannabinols and (-)-7-hydroxy-delta-1-tetrahydrocannabinol to blood cells and plasma proteins in man. $J$ Pharm Pharmacol. 1974;26:914-916.

13. Wahlqvist M, Nilsson IM, Sandberg F, et al. Binding of delta-1tetrahydrocannabinol to human plasma proteins. Biochem Pharmacol. 1970;19:2579-2584.

14. Owens SM, McBay AJ, Reisner HM, et al. 125I radioimmunoassay of delta-9-tetrahydrocannabinol in blood and plasma with a solidphase second-antibody separation method. Clin Chem. 1981;27: 619-624.

15. Mason AP, McBay AJ. Cannabis: pharmacology and interpretation of effects. J Forensic Sci. 1985;30:615-631.

16. Giroud C, Menetrey A, Augsburger M, et al. Delta(9)-THC, 11-OHDelta(9)-THC and Delta(9)-THCCOOH plasma or serum to whole blood concentrations distribution ratios in blood samples taken from living and dead people. Forensic Sci Int. 2001;123:159-164.

17. Huang W, Moody DE, Andrenyak DM, et al. Simultaneous determination of delta9-tetrahydrocannabinol and 11-nor-9-carboxy-delta9-tetrahydrocannabinol in human plasma by solid-phase extraction and gas chromatography-negative ion chemical ionization-mass spectrometry. J Anal Toxicol. 2001;25:531-537.

18. Hunt CA, Jones RT. Tolerance and disposition of tetrahydrocannabinol in man. $J$ Pharmacol Exp Ther. 1980;215:35-44.
19. Lemberger L, Tamarkin NR, Axelrod J, et al. Delta-9-tetrahydrocannabinol: metabolism and disposition in long-term marihuana smokers. Science. 1971;173:72-74.

20. Ho BT, Fritchie GE, Kralik PM, et al. Distribution of tritiated-1 delta 9tetrahydrocannabinol in rat tissues after inhalation. $J$ Pharm Pharmacol. 1970;22:538-539.

21. Agurell S, Nilsson IM, Ohlsson A, et al. On the metabolism of tritium-labeled 1-tetrahydrocannabinol in the rabbit. Biochem Pharmacol. 1970;19:1333-1339.

22. Johansson E, Noren K, Sjovall J, et al. Determination of delta 1tetrahydrocannabinol in human fat biopsies from marihuana users by gas chromatography-mass spectrometry. Biomed Chromatogr. 1989;3:35-38.

23. Kreuz DS, Axelrod J. Delta-9-tetrahydrocannabinol: localization in body fat. Science. 1973;179:391-393.

24. Harvey DJ, Leuschner JT, Paton WD. Gas chromatographic and mass spectrometric studies on the metabolism and pharmacokinetics of delta 1-tetrahydrocannabinol in the rabbit. J Chromatogr. 1982; 239:243-250.

25. Haggerty GC, Deskin R, Kurtz PJ, et al. The pharmacological activity of the fatty acid conjugate 11-palmitoyloxy-delta 9-tetrahydrocannabinol. Toxicol Appl Pharmacol. 1986;84:599-606.

26. Leighty EG, Fentiman AF Jr, Foltz RL. Long-retained metabolites of delta9- and delta8-tetrahydrocannabinols identified as novel fatty acid conjugates. Res Commun Chem Pathol Pharmacol. 1976;14: 13-28.

27. Reiter A, Hake J, Meissner C, et al. Time of drug elimination in chronic drug abusers. Case study of 52 patients in a "low-step" detoxification ward. Forensic Sci Int. 2001;119:248-253.

28. Daldrup T, Thomsen T, Reudenbach G. Cannabiskonsum: Nachweisdauer, zeitlicher Verlauf, forensische Bedeutung. In: Arnold W, Poser WE, Möller MR, eds. Suchtkrankheiten. Diagnose, Therapie and analytische Nachweise. Berlin: Springer-Verlag; 1988:39-51.

29. Chiang CN, Rapaka RS. Pharmacokinetics and disposition of cannabinoids. NIDA Res Monogr. 1987;79:173-188.

30. Kelly P, Jones RT. Metabolism of tetrahydrocannabinol in frequent and infrequent marijuana users. J Anal Toxicol. 1992;16:228-235.

31. Huestis MA, Cone EJ. Urinary excretion half-life of 11-nor-9carboxy-delta9-tetrahydrocannabinol in humans. Ther Drug Monit. 1998;20:570-576.

32. Johansson EK, Hollister LE, Halldin MM. Urinary elimination half-life of delta-1-tetrahydrocannabinol-7-oic acid in heavy marijuana users after smoking. NIDA Res Monogr. 1989;95:457-458.

33. Manno JE, Manno BR, Kemp PM, et al. Temporal indication of marijuana use can be estimated from plasma and urine concentrations of delta9-tetrahydrocannabinol, 11-hydroxy-delta9-tetrahydrocannabinol, and 11-nor-delta9-tetrahydrocannabinol-9carboxylic acid. J Anal Toxicol. 2001;25:538-549.

34. Dugan S, Bogema S, Schwartz RW, et al. Stability of drugs of abuse in urine samples stored at $-20^{\circ}$ C. J Anal Toxicol. 1994;18:391-396.

35. Golding Fraga S, Diaz-Flores Estevez J, Diaz Romero C. Stability of cannabinoids in urine in three storage temperatures. Ann Clin Lab Sci. 1998;28:160-162.

36. Skopp G, Pötsch L. Stability of 11-nor-delta(9)-carboxy-tetrahydrocannabinol glucuronide in plasma and urine assessed by liquid chromatography-tandem mass spectrometry. Clin Chem. 2002;48: 301-306

37. Skopp G, Pötsch L. An investigation of the stability of free and glucuronidated 11-nor-delta9-tetrahydrocannabinol-9-carboxylic acid in authentic urine samples. J Anal Toxicol. 2004;28:35-40.

38. Cone EJ, Johnson RE, Paul BD, et al. Marijuana-laced brownies: behavioral effects, physiologic effects, and urinalysis in humans following ingestion. J Anal Toxicol. 1988;12:169-175.

39. Huestis MA, Mitchell JM, Cone EJ. Detection times of marijuana metabolites in urine by immunoassay and GC-MS. J Anal Toxicol. 1995; 19:443-449.

40. Huestis MA, Mitchell JM, Cone EJ. Urinary excretion profiles of 11-nor-9-carboxy-delta 9-tetrahydrocannabinol in humans after single smoked doses of marijuana. J Anal Toxicol. 1996;20:441-452.

41. Smith-Kielland A, Skuterud B, Morland J. Urinary excretion of 11-nor-9-carboxy-delta9-tetrahydrocannabinol and cannabinoids in 
frequent and infrequent drug users. J Anal Toxicol. 1999;23: 323-332.

42. Niedbala RS, Kardos KW, Fritch DF, et al. Detection of marijuana use by oral fluid and urine analysis following single-dose administration of smoked and oral marijuana. J Anal Toxicol. 2001;25: 289-303.

43. Hollister LE, Kanter SL. Laboratory Verification of "heavy" and "light" users of cannabis. Drug Alcohol Depend. 1980;5:151-152.

44. Dackis CA, Pottash AL, Annitto W, et al. Persistence of urinary marijuana levels after supervised abstinence. Am J Psychiatry. 1982;139:1196-1198.

45. Ellis GM Jr, Mann MA, Judson BA, et al. Excretion patterns of cannabinoid metabolites after last use in a group of chronic users. Clin Pharmacol Ther. 1985;38:572-578.

46. Lafolie P, Beck O, Blennow G, et al. Importance of creatinine analyses of urine when screening for abused drugs. Clin Chem. 1991;37:1927-1931.

47. Kielland KB. [Urinary excretion of cannabis metabolites.] Tidsskr Nor Laegeforen. 1992;112:1585-1586.

48. Fraser AD, Coffin L, Worth D. Drug and chemical metabolites in clinical toxicology investigations: the importance of ethylene glycol, methanol and cannabinoid metabolite analyses. Clin Biochem. 2002;35:501-511.

49. Bell R, Taylor EH, Ackerman B, et al. Interpretation of urine quantitative 11-nor-delta-9 tetrahydrocannabinol-9-carboxylic acid to determine abstinence from marijuana smoking. J Toxicol Clin Toxicol. 1989;27:109-115.

50. Huestis MA, Cone EJ. Differentiating new marijuana use from residual drug excretion in occasional marijuana users. $J$ Anal Toxicol. 1998;22:445-454.

51. Manno JE, Ferslew KE, Manno BR. Urine excretion patterns of cannabinoids and the clinical application of the EMIT dau cannabinoid urine assay for substance abuse treatment. In: Agurell S, Dewey WL, Willette R, eds. The Cannabinoids: Chemical, Pharmacologic and Therapeutic Aspects. New York: Academic Press; 1984:281-290.

52. Fraser AD, Worth D. Urinary excretion profiles of 11-nor-9carboxy-Delta9-tetrahydrocannabinol: a delta9-THCCOOH to creatinine ratio study. J Anal Toxicol. 1999;23:531-534.

53. Fraser AD, Worth D. Urinary excretion profiles of 11-nor-9carboxy-Delta9-tetrahydrocannabinol: a Delta9-THC-COOH to creatinine ratio study \#2. Forensic Sci Int. 2003;133:26-31.

54. Fraser AD, Worth D. Urinary excretion profiles of 11-nor-9carboxy-Delta9-tetrahydrocannabinol. Study III. A Delta9-THC$\mathrm{COOH}$ to creatinine ratio study. Forensic Sci Int. 2003;137: 196-202.

55. Alburges ME, Peat MA. Profiles of delta 9-tetrahydrocannabinol metabolites in urine of marijuana users: preliminary observations by high performance liquid chromatography-radioimmunoassay. J Forensic Sci. 1986;31:695-706.

56. Skopp G, Pötsch L, Ganßmann B, et al. Freie und glucuronidierte Cannabinoide im Urin-Untersuchungen zur Einschätzung des Konsumverhaltens. Rechtsmed. 1999;10:21-28.

57. Hanson VW, Buonarati MH, Baselt RC, et al. Comparison of $3 \mathrm{H}-$ and 125I-radioimmunoassay and gas chromatography/mass spectrometry for the determination of delta 9-tetrahydrocannabinol and cannabinoids in blood and serum. J Anal Toxicol. 1983;7:96-102.

58. Foltz RL, McGinnis KM, Chinn DM. Quantitative measurement of delta 9-tetrahydrocannabinol and two major metabolites in physiological specimens using capillary column gas chromatography negative ion chemical ionization mass spectrometry. Biomed Mass Spectrom. 1983;10:316-323.

59. Huestis MA, Henningfield JE, Cone EJ. Blood cannabinoids. II. Models for the prediction of time of marijuana exposure from plasma concentrations of delta 9-tetrahydrocannabinol (THC) and 11-nor-9-carboxy-delta 9-tetrahydrocannabinol (THCCOOH). $J$ Anal Toxicol. 1992;16:283-290.

60. Smith ML, Wesenyalsh N, Barnes A, et al. Estimating time of last oral ingestion of cannabis from plasma $\mathrm{THC}$ and $\mathrm{THCCOOH}$ concentrations. Abstract book: 43rd International Meeting of the International Association of Forensic Toxicologists (TIAFT), Seoul (South Korea), 2005:82.

61. Daldrup T. Cannabis im Straßenverkehr; Abschlußbericht Z.B. 3.4721/03-2/93. Düsseldorf: Ministerium für Wirtschaft Mittelstand, Technologie und Verkehr NRW; 1996.

62. Drasch G, von Meyer L, Roider G, et al. Absolute Fahruntüchtigkeit unter der Wirkung von Cannabis-Vorschlag für einen Grenzwert. Blutalkohol. 2003;40:269-286.

63. Daldrup T, Meininger I. Begutachtung der Fahrtüchtigkeit unter Cannabis im Straßenverkehr. In: Berghaus G, Krüger H-P, eds. Cannabis im Straßenverkehr. Stuttgart: G. Fischer; 1998:153-178.

64. Daldrup T. Traffic accidents after cannabis use. Presentation 6th International Symposium on Advances in Legal Medicine (ISALM), Hamburg, September 19-24, 2005.

65. Daldrup T, Käferstein H, Köhler H, et al. Entscheidung zwischen einmaligem/gelegentlichem und regelmäßigem Cannabiskonsum. Blutalkohol. 2000;37:39-47.

66. Sachs H, Kintz P. Testing for drugs in hair. Critical review of chromatographic procedures since 1992. J Chromatogr B Biomed Sci Appl. 1998;713:147-161

67. Madea B, Musshoff F. Haaranalytik-Technik und Interpretation in Medizin und Recht. Köln: Deutscher Ärzteverlag; 2004.

68. Nakahara Y, Takahashi K, Kikura R. Hair analysis for drugs of abuse. X. Effect of physicochemical properties of drugs on the incorporation rates into hair. Biol Pharm Bull. 1995;18:1223-1227.

69. Mieczkowski T, Newel R. Comparing hair and urine assays for cocaine and marijuana. Fed Probat. 1993;57:59-67.

70. Mieczkowski T, Newel R, Wraight B. Using hair analysis, urinalysis, and self-reports to estimate drug use in a sample of detained juveniles. Subst Use Misuse. 1998;33:1547-1567.

71. Musshoff F, Driever F, Lachenmeier K, et al. Results of hair analyses for drugs of abuse and comparison with self-reports and urine tests. Forensic Sci Int. 2006;156:118-123.

72. Mieczkowski T. A research note: the outcome of GC/MS/MS confirmation of hair assays on 93 cannabinoid $(+)$ cases. Forensic Sci Int. 1995;70:83-91.

73. Uhl M. Tandem mass spectrometry: a helpful tool in hair analysis for the forensic expert. Forensic Sci Int. 2000;107:169-179.

74. Moore C, Guzaldo F, Donahue T. The determination of 11-nordelta9-tetrahydrocannabinol-9-carboxylic acid (THC-COOH) in hair using negative ion gas chromatography-mass spectrometry and high-volume injection. J Anal Toxicol. 2001;25:555-558.

75. Sachs H, Dressler U. Detection of THCCOOH in hair by MSD-NCI after HPLC clean-up. Forensic Sci Int. 2000;107:239-247.

76. Baptista MJ, Monsanto PV, Pinho Marques EG, et al. Hair analysis for delta(9)-THC, delta(9)-THC-COOH, CBN and CBD, by GC MS-EI. Comparison with GC/MS-NCI for delta(9)-THC-COOH. Forensic Sci Int. 2002;128:66-78.

77. Uhl M, Sachs H. Cannabinoids in hair: strategy to prove marijuana/ hashish consumption. Forensic Sci Int. 2004;145:143-147. 